\title{
Methyl Methacrylate and Alpha-Methylstyrene: New Strategy for Synthesis of Bloc Copolymers for Use in Potential Biomedical Applications Generated by an Ecologic Catalyst Called Maghnite (Algerian MMT)
}

\author{
Moulkheir Ayat, Mohamed Belbachir, Abdelkader Rahmouni* \\ Laboratory of Polymer Chemistry, Department of Chemistry, Faculty of Sciences, Oran1. \\ Université Ahmed Benbella, BP 1524.El M’nouar. 31000 Oran, Algeria
}

Received: $2^{\text {nd }}$ May 2015; Revised: 24th February 2016; Accepted: 15th March 2016

\section{Abstract}

A new model for synthesis of the plastics, block copolymers were prepared from methyl methacrylate (MMA) and alpha-methyl styrene ( $\alpha$-MS) by cationic copolymerization in the presence of a new and efficient catalyst of "Maghnite-Na" at $0{ }^{\circ} \mathrm{C}$ in bulk. In this paper, the copolymerization of $a$-MS and MMA was induced in heterogeneous phase catalyzed by Maghnite-Na was investigated under suitable conditions. The "Maghnite-Na" is a montmorillonite sheet silicate clay, with exchanged sodium cations to produce Na-Montmorillonite $\left(\mathrm{Na}^{+}-\mathrm{MMT}\right)$ obtained from Tlemcen, Algeria, was investigated to remove heavy metal ion from wastewater as an efficient catalyst for cationic polymerization of many vinylic and heterocyclic monomers. The synthesized copolymer were characterized by Nuclear Magnetic Resonance (NMR-1 H, NMR-13C), FT-IR spectroscopy, Differential Scanning Calorimetry (DSC), and Gel Permeation Chromatography (GPC) to elucidate structural characteristics and thermal properties of the resulting copolymers. The structure compositions of "MMT", "H+-MMT" and "Na+. MMT" have been developed. The effect of the MMA $/ a$-MS molar ratio on the rate of copolymerization, the amount of catalyst, temperature and time of copolymerization on yield of copolymers was studied. The yield of copolymerization depends on the amount of $\mathrm{Na}^{+}$-MMT used and the reaction time. The kinetic studies indicated that the polymerization rate is first order with respect to monomer concentration. A possible mechanism of this cationic polymerization is discussed based on the results of the ${ }^{1} \mathrm{H}$-NMR Spectroscopic analysis of these model reactions. A cationic mechanism for the reaction studies showed that monomer was inserted into the growing chains. Copyright (C) 2016 BCREC GROUP. All rights reserved

Keywords: catalyst; clay; Na-montmorillonite; cationic copolymerization; methyl methacrylate; alphamethyl styrene; block copolymerization; mechanism

How to Cite: Ayat, M., Belbachir, M., Rahmouni, A. (2016). Methyl Methacrylate and Alpha-Methyl Styrene: New Strategy for Synthesis of Bloc Copolymers for Use in Potential Biomedical Applications Generated by an Ecologic Catalyst Called Maghnite (Algerian MMT). Bulletin of Chemical Reaction Engineering \& Catalysis, 11 (3): 316-329 (doi: 10.9767/bcrec.11.3.571.316-329)

Permalink/DOI: http://doi.org/10.9767/bcrec.11.3.571.316-329

* Corresponding Author.

E-mail: ramaek23@yahoo.fr (A. Rahmouni)

\section{Introduction}

A new model has been developed for the preparing plastics polymers. Recently, the aliphatic and aromatic polymers, in particular poly(a-MS), poly(MMA), and their copolymers, 
the variety of binary initiating systems consisting of a protonic acid and a Lewis acid have been reported to induce the living polymerizations of cationically polymerizable vinyl monomers [1-9]. Cationic polymerization was a widely used method for preparing hydrocarbon polymers [10]. Numerous examples of the polymerization of vinyl monomers by a cationic pathway using various Lewis acids, such as: $\mathrm{AlCl}_{3}$ [11], $\mathrm{BF}_{3}[12], \mathrm{SnCl}_{4}$ [13], and $\mathrm{TiCl}_{4}$ [14] catalyst systems, can be found in the literature. These homogenous polymerization reactions are fast and efficient, using cheap catalysts, but molecular weight control is generally poor. Moreover, these homogeneous Lewis acid catalysts present some major drawbacks: their corrosive nature makes them difficult to handle and they are difficult to separate from the reaction products. Indeed the catalyst has to be removed from the polymer by a water-quenching step that not only destroys the Lewis acid making reuse impossible but also leads to a large volume of acidic aluminum waste, unacceptable in these environmentally conscious days $[15,16]$. Methyl Methacrylate (MMA) copolymers have a number of excellent characteristics which have placed them in a position of prominence in the plastic industry.

The preparation of poly(methyl methacrylate) (PMMA) plastics and their characteristic structure properties have been thoroughly investigated in recent years [17-20]. This polymer have a several applications such as material chemistry, biological medicine and environmental science [21-25]. Many researchers have reported fabrication of poly Alpha-Methyl Styrene (PAMS) / clay nanocomposites [26-30], polyMethyl Methacrylate (PMMA) / clay nanocomposites and poly styrene-co-methyl methacrylate (PSco-PMMA) / Na-MMT nanocomposites because of many advantages such as high mechanical property, good gas barrier, flame retardation and, etc. [31,33], polymer/clay nanocomposites have been intensely investigated by researchers at Toyota for light-weight material applications [34-41]. The cationic polymerization of MMA seems unlikely in view of it structure, Lewis acid catalysis explains the difficulties encountered in trying fabricate plastics. Other attempts to induce cationic copolymerization of methyl methacrylate have been unsuccessful $[42,43]$. There is, to date, no information on the polymerization of MMA with $\mathrm{Na}^{+}$-MMT catalyst. In continuation of our studies on environmentally benign methods using solid supports, we report for the first time and present a new approach to synthesis of poly(AMS/MMA) via cationic polymerization using a $\mathrm{Na}^{+}$-MMT [44-46]. In our previous papers, we already reported about polymerization catalyzed by "Na+-MMT", this new nontoxic cationic catalyst exhibited higher efficiency via the polymerization of vinylic and hetero-cyclic monomers [47-57].

The objectives of this work are the synthesis of block copolymers of poly (MMA-b-AMS) by the use of $\mathrm{Na}^{+}$-MMT as catalyst. The interesting aspect of this new non-toxic catalyst is the environmentally friendly nature of the reaction because it does not imply the disposal of solvents or metal catalysts. This catalyst can be easily separated from the copolymer product and regenerated by heating at a temperature above $100{ }^{\circ} \mathrm{C}$ [44-46]. The effects of different synthesis parameters such as the amount of $\mathrm{Na}^{+}$-MMT, comonomer AMS, and eventually the mechanism are discussed.

\section{Materials and Method}

\subsection{Materials}

Methyl methacrylate (99\%) and $a$-methyl styrene (99\%) were purchased from Aldrich (Paris, France) were purified by fractional distillation under reduced pressure. Methanol and 1,4-dioxane were dried over magnesium sulfate $\mathrm{MgSO}_{4}$ and distilled. (Aldrich Chemical) were used as received. Raw-bentonite: Algerian Montmorillonite clay, was procured from "BENTAL" (Algerian Society of Bentonite).

\subsection{Preparation of the sodic montmorillo- nite (Na+-MMT)}

The bentonite used in this work came from a quarry located in Maghnia (North West of Algeria) and was supplied by company "ENOF" (an Algerian manufacture specialized in the production of no ferric products and useful substances). Figure 1 and Table 1 show X-ray diffraction patterns of raw-Montmorillonite and Na-Montmorillonite. These results confirm that the bentonite used consists essentially of montmorillonite, prepared in laboratory chemistry of polymers in ORAN University (LCPO). This Clay was purified by separation of the argillaceous phase and the coarse phases. Rough clay was put in suspension in distilled water. In the suspension, the solid/liquid report/ratio was approximately $1 / 10$. The suspension was then filtered on a sieve $0.02 \mathrm{~mm}$ in diameter of pores to eliminate the coarse matter and stones. It 
then versed in test-tubes and was left at rest during 2 hours. The separation of the argillaceous phase of the coarse fraction which remains at the bottom was made by siphoning. The recovered suspension was then centrifuged with $4500 \mathrm{rpm}$ during $20 \mathrm{~min}$. Recovered clay was treated with a solution of $1 \mathrm{M}$ of sodium hexametaphosphate $\left(\mathrm{NaPO}_{3}\right)_{6}$ (clay $20 \mathrm{~g}$ in 100 $\mathrm{mL}$ ), by maintaining agitation, during $3 \mathrm{~h}$. The suspension was versed then in the test-tubes of separation and Na-Montmorillonite was separated while exploiting its falling speed, Mont- morillonite crosses with $20^{\circ} \mathrm{C}$, a distance of 10 $\mathrm{cm}$ each $8 \mathrm{~h}$. Therefore Na-Montmorillonite was recovered by siphoning at a distance of $20 \mathrm{~cm}$ after $16 \mathrm{~h}$ of decantation. One adds water distilled to the test-tubes. After each siphoning, one agitated during $15 \mathrm{~min}$ and one let the suspension to be elutriated before proceeding to new a siphoning. Montmorillonite was then recovered by centrifugation with $4500 \mathrm{rpm}$ during $1 \mathrm{~h}$. With the end, it was washed with distilled water (on several occasions), filtered using one sintered of porosity 3 (maximum di-

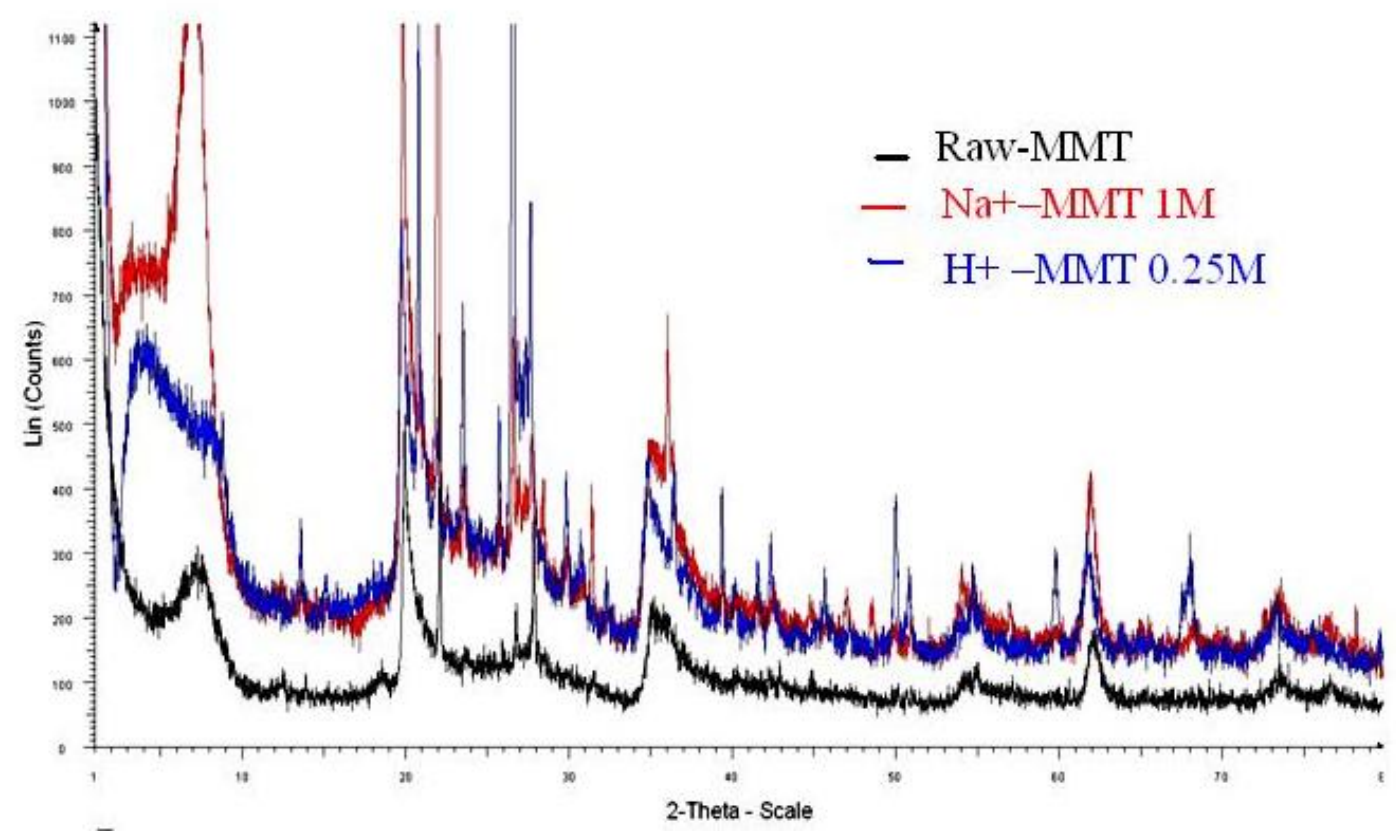

Figure 1. Experimental set-up for glycerol dry reforming

Table 1. Comparison in the RX characteristic of American and Maghnia Algerian Bentonites

\begin{tabular}{|c|c|c|c|c|c|c|c|c|c|c|}
\hline & \multicolumn{2}{|c|}{ Montmorillonite } & \multicolumn{2}{|c|}{ Quartz } & \multicolumn{2}{|c|}{ Dolomite } & \multicolumn{2}{|c|}{ Calcite } & \multicolumn{2}{|c|}{ Smectite } \\
\hline & $\theta$ & $\mathrm{d}$ & $\theta$ & $\mathrm{d}$ & $\theta$ & $\mathrm{d}$ & $\theta$ & $\mathrm{d}$ & $\theta$ & $\mathrm{d}$ \\
\hline \multirow{4}{*}{$\begin{array}{c}\text { Bentonite } \\
\text { (Wyoming) [61] }\end{array}$} & 4.50 & 9.69 & 13.50 & 3.35 & 23.75 & 1.91 & 19.5 & 2.28 & 31.0 & 1.50 \\
\hline & 10.00 & 4.48 & 11.00 & 4.05 & - & - & 13.75 & 3.20 & - & - \\
\hline & 17.50 & 2.56 & 12.00 & 3.76 & - & - & - & - & - & - \\
\hline & 27.25 & 1.69 & 34.50 & 1.36 & - & - & - & - & - & - \\
\hline MMT & 4.50 & 9.692 & 13.40 & 3.349 & 15.75 & 2.848 & 14.95 & 3.001 & 31.0 & 1.497 \\
\hline Brute & 10.00 & 4.485 & 11.00 & 4.045 & - & - & 18.25 & 2.488 & - & - \\
\hline \multirow{2}{*}{ [44-46] } & 17.50 & 2.557 & 11.75 & 3.782 & - & - & 13,90 & 3.222 & - & - \\
\hline & 27.00 & 1.692 & 36.25 & 1.287 & - & - & - & - & - & - \\
\hline Bentonite & 3.5 & 12.79 & - & - & - & - & 14.0 & 3.13 & 31.0 & 1.50 \\
\hline \multirow[t]{3}{*}{$\mathrm{Na}^{+}[61]$} & 9.95 & 4.51 & - & - & - & - & - & - & - & - \\
\hline & 17.45 & 2.58 & - & - & - & - & - & - & - & - \\
\hline & 27.25 & 1.69 & - & - & - & - & - & - & - & - \\
\hline $\mathrm{Na}^{+}$-MMT & 3.50 & 12.766 & 26.59 & 3.347 & 15.75 & 2.847 & 14.0 & 3.221 & 31.0 & 1.496 \\
\hline \multirow[t]{3}{*}{ [44-46] } & 10.00 & 4.483 & 20.76 & 4.045 & - & - & 14.25 & 3.136 & - & - \\
\hline & 17.50 & 2.557 & - & 3.774 & - & - & 18,5 & 2.490 & - & - \\
\hline & 27.00 & 1.696 & - & 1.286 & - & - & - & - & - & - \\
\hline \multirow[t]{4}{*}{$\mathrm{H}^{+}-\mathrm{MMT}[44-46]$} & 8.74 & 10.097 & 20.75 & 4.274 & - & - & 29.81 & 2.993 & 59.82 & 1.544 \\
\hline & 19.71 & 4.498 & 26.55 & 3.353 & - & - & 27.35 & 3.256 & 61.81 & 1.499 \\
\hline & 34.54 & 2.593 & - & - & - & - & 27.62 & 3.225 & - & - \\
\hline & 54.77 & 1.674 & - & - & - & - & - & - & - & - \\
\hline
\end{tabular}


ameter of pores from 16 to $40 \mu \mathrm{m}$ ), dried in the drying oven with $100{ }^{\circ} \mathrm{C}$, crushed using a mortar and kept in a desiccator $[58,59]$.

\subsection{Catalyst structure}

Various methods of analysis, such as: 27Al and 29Si MAS NMR, show that Maghnia Algerian Bentonite is a montmorillonite sheet silicate clay $[47,48]$. Figure 1 (a, b, c) and Table 1 show X-ray diffraction patterns of rawmontmorillonite, $\mathrm{H}^{+}-\mathrm{MMT}$ and $\mathrm{Na}^{+}-\mathrm{MMT}$, respectively. The basal spacing of the raw- montmorillonite and $\mathrm{Na}^{+}$-MMT, were exhibited $12.766 \AA$ and $10.097 \AA$, respectively. The titration of raw-montmorillonite with a solution $1 \mathrm{M}$ $\left(\mathrm{NaPO}_{3}\right)_{6}$ and $0.25 \mathrm{M} \mathrm{H}_{2} \mathrm{SO}_{4}$ resulted in the exchange of exchangeable cations for $\mathrm{H}^{+}$and $\mathrm{Na}^{+}$ in the interlayer. The X-ray powder diffraction of the dried $\mathrm{Na}^{+}-\mathrm{MMT}$, as shown in Figure 1(c), exhibited 001 reflections corresponding to basal spacing of $9.69 \AA$ A. Yun Kwon et al. [60] reported that the decrease in the basal spacing indicates a loss of the interlayer $\mathrm{H}_{2} \mathrm{O}$ upon the replacement of $\mathrm{Na}^{+}$for $\mathrm{H}^{+}$. In particular, although the $\mathrm{X}$-ray peak of the montmorillonite did not change substantially before or after the sodium hexametaphosphate treatment, there was a decrease in the basal spacing. This implies that the original structure was well preserves after the sodium hexametaphosphate treatment.

\subsection{Polymerization procedure}

The polymerization of MMA/AMS was carried out in a heterogeneous system, using $\mathrm{Na}^{+}$MMT as a catalyst in different molar ratios were copolymerized by bulk polymerization, The bulk Copolymers of various compositions of a-methyl styrene and methyl methacrylate were prepared by a cationic polymerization process at $0{ }^{\circ} \mathrm{C}$ with $0.23 \mathrm{~g}$ initiator $\mathrm{Na}^{+}-\mathrm{MMT}$ under a certain reaction time. The reaction scheme is shown in Figure 2. The resulted polymer was dissolved in 1.4-dioxane, precipitated in cold methanol, and then airdried at room temperature. The above procedure was repeated several times in order to obtain a highly purified polymer.

\subsection{Polymer characterization}

The copolymers were re-dissolved in 1.4 dioxane and precipitated into methanol 3 times before characterization. Fourier Transform Infrared (FT-IR) spectroscopy (Alpha-Bruker) was used to confirm the structure of PAMS-PMMA block copolymers. ${ }^{1} \mathrm{H}$ and ${ }^{13} \mathrm{C}$ nuclear magnetic resonance (NMR) measurements were carried out on a $300 \mathrm{MHz}$ Bruker spectrometer equipped with a probe $\mathrm{BB} 05 \mathrm{~mm}$, in $\mathrm{CDCl}_{3}$ solution under ambient temperature using tetramethyl silane (TMS) as internal standard in these cases. Gel-permeation chromatography was performed with a Spectra-Physics chromatograph, equipped with four columns connected in series, and packed with Ultrastyragel $10^{3}, 10^{4}, 10^{5}, 10^{6}$ $\mathrm{A}^{\circ} \mathrm{THF}$ was used as solvent and the instrument was calibrated to a first approximation with polystyrene of known molecular weights.

Viscosity measurements were carried out with an Ubbelohde capillary viscosimeter (viscologic TI1, version 3-1 Semantec). Intrinsic viscosity, $[\eta](\mathrm{mL} / \mathrm{g})$, was measured at $25^{\circ} \mathrm{C}$ in THF. Viscosity-average molecular weight, $\mathrm{M}_{\mathrm{v}}$, was calculated according to the equation (1) [62].

$$
[\eta]=10.1 \times 10^{-3} \mathrm{Mv} 0.71
$$

Thermal analysis of poly (MMA-b-AMS) was conducted on a differential calorimetry apparatus $(200 \quad \mathrm{PC} \quad \mathrm{NETZCH}, \quad 204 \mathrm{~F} 1$ PHOENIX240-12-0110-L DSC) the measurements were carried out with a heating rate of $10 \circ \mathrm{C} / \mathrm{min}$ under $50 \mathrm{~cm}^{3} / \mathrm{min}$ nitrogen flow.

\section{Results and Discussion}

The purpose of this paper is the synthesis of poly (MMA-b-AMS) by bulk polymerization catalyzed by $\mathrm{Na}^{+}-\mathrm{MMT}$ [44-46]. Montmorillonites have both Brønsted and Lewis acid sites and when exchanged with cations having a high charge density, as sodiums, produce highly active catalysts for sodium Hexametaphosphate catalyzed reactions. Intercalated organic molecules are mobile and can be highly polarized when situated in the<smiles>C=C(C)C(C)=O</smiles>

Figure 2. Reaction Scheme of AMS and MMA copolymerization 
space between the charged clay layers. These exchanged montmorillonites have been successfully used as catalysts for the reactions of polymerization [61].

The aim of this research is to extend the scope of other promising new field of polymer synthesis by the use of another catalyst system that has been shown to exhibit higher efficiency. This study is also concerned with polymerization and examines the catalytic activity of an Algerian sodiums-exchanged montmorillonite clay called " $\mathrm{Na}^{+}-\mathrm{MMT}$ " via cationic copolymerization of methyl methacrylate (MMA) and a-MethylStyrene (AMS). The structure and the composition of the catalyst were reported in previous works [44-46].

\subsection{Synthesis of poly(MMA-b-a-MS) by sodic montmorillonite}

We intended to prepare poly(MMA-b-a-MS) block copolymers by cationic polymerization with 30\% a-MS and 70\% MMA in the presence of $15 \% \mathrm{Na}+\mathrm{MMT}$ as a catalyst for $48 \mathrm{~h}$ at $0{ }^{\circ} \mathrm{C}$. The catalyst was dried in an oven at $120{ }^{\circ} \mathrm{C}$ overnight and then transferred to a vacuum desiccators containing $\mathrm{P}_{2} \mathrm{O}_{5}$ to cool to room temperature overnight. The reaction was carried out in tubes sealed and immersed in an glazing bath at $0{ }^{\circ} \mathrm{C}$. Each tube contains an amount of a-MS (0.013 mole, $1.54 \mathrm{~g})$ which contains $0.23 \mathrm{~g}(15 \%)$ of $\mathrm{Na}^{+}$-MMT, the system is put under mechanical agitation during 10 min; when the mixture becomes viscous and at the end of reaction we added thereafter the second monomer $3 \mathrm{~g}$ (0.031 mole) of MMA, the mixture is left under agitation during $48 \mathrm{~h}$. When the reaction time to be over, the polymer was dissolved with $20 \mathrm{~mL}$ of 1.4 dioxane to remove the clay and precipitated in cold methanol, after polymerization the samples were filtered and dried in vacuum. The precipitates were characterized by ${ }^{1} \mathrm{H}-\mathrm{NMR}$,
${ }^{13} \mathrm{C}-\mathrm{NMR}$, and infrared spectroscopy (FT-IR) analysis. The results are shown in Table 2 , The proof for this copolymerization was obtained by GPC measurements, Chromatogram. The results of the analysis of the polymer by GPC are shown in Figure 3. As shown, the macromolecular weight distribution of the obtained polymer is narrow, this suggests that chain transfer does not occur.

\subsection{Effect of the amount of MMT-Na+ on copolymerization}

The results of experiments of $a$-methyl styrene copolymerization induced by ${ }^{~} \mathrm{Na}^{+}$MMT $1 \mathrm{M}^{\prime \prime}$ are reported in Table 3, shown the effect of the amount of $\mathrm{Na}^{+}$-MMT on the copolymerization of AMS and MMA. Indeed, using various amounts of $\mathrm{Na}^{+}-\mathrm{MMT}, 10,13,15$, 18 and $20 \%$ by weight, the polymerization of AMS with MMA was carried in bulk at $0{ }^{\circ} \mathrm{C}$. The amount of catalyst $\left(\mathrm{Na}^{+}-\mathrm{MMT} / \mathrm{AMS}\right)$ was an important factor of polymerization. We can see from Table 3, that the polymerization rate increased with the amount of $\mathrm{Na}^{+}$-MMT, in which the effect of $\mathrm{Na}^{+}$-MMT as a cationic catalyst for AMS/MMA polymerization is clearly shown. This phenomenon is probably the result of the number of "initiating active sites" responsible of inducing polymerization, this number is prorating to the catalyst amount used in reaction. also it explained by an increase in the number of chain in propagation in presence of a great quantity of catalyst. We can see also in Table 3 , the molecular weight are proportional to the amount of $\mathrm{Na}^{+}$-MMT. Similar results are obtained by Ayat et al. [46] and Harrane et al. [63], in the polymerization of a-methyl styrene; diblock copolymers of glycolide and poly(oxyethylene) using a $\mathrm{Mag}-\mathrm{H}^{+}$as catalyst, respectively.

Table 2. Effect of molar ratio on the copolymerization of AMS $\left(\mathrm{M}_{1}\right)$ with $\mathrm{MMA}\left(\mathrm{M}_{2}\right)$ at $0^{\circ} \mathrm{C}$, in bulk

\begin{tabular}{cccccc}
\hline Sample N & molar ratio [AMS /MMA] & Time in hours & Yield (\%) & Mn (g/mol) & Mw/Mn \\
\hline 1 & $70 / 30$ & 9 & 12 & 2212 & 1.74 \\
2 & $60 / 40$ & 16 & 20 & 2341 & 1.64 \\
3 & $50 / 50$ & 20 & 28 & 2575 & 1.97 \\
4 & $40 / 60$ & 24 & 34 & 2685 & 1.71 \\
5 & $30 / 70$ & 48 & 54 & 3994 & 1.34 \\
\hline
\end{tabular}

a Determined by GPC according to polyTHF standards, $\mathrm{Na}^{+}$-MMT/AMS: $15 \%$ (w/w) T= $=0^{\circ} \mathrm{C}$ 


\subsection{Characterization of copolymers}

\subsubsection{GPC study}

The gel permeation chromatogram of the block copolymer shows that the molecular weight are proportional to the polymer yield. The molecular weight distribution is widened with the increase of MMA and decreased with AMS in the monomer ratio. It indicates that the polymer with more MMA content (or less AMS content). The same results are obtained by Guo et al. [64].

\subsubsection{Infrared spectroscopy}

The IR spectrum (Figure 4) and Table 4 of copolymer shows band at $3000 \mathrm{~cm}^{-1}$ due to aromatic C-H str vibrations, 2927 and 2850 $\mathrm{cm}^{-1}$ due to $\mathrm{C}-\mathrm{H}$ str vibrations of methyl, methylene and methine groups, $1730 \mathrm{~cm}^{-1}$ due to $>\mathrm{C}=\mathrm{O}$ str vibrations of ester carbonyl, $1600 \mathrm{~cm}^{-1}$ due to aromatic $\mathrm{C}=\mathrm{C}$ str vibrations,

Table 3. Evolution of the yield and the number - average molecular weight according to amount of MMT- $\mathrm{Na}^{+}$on the copolymerization ${ }^{\mathrm{b}}$

\begin{tabular}{ccccc}
\hline $\begin{array}{c}\text { Sample } \\
\mathrm{N}^{\circ}\end{array}$ & $\begin{array}{c}\text { Catalyst } \\
\text { in \% }\end{array}$ & $\begin{array}{c}\text { Yield } \\
\text { in \% }\end{array}$ & Mn & Mw/ Mn \\
\hline 1 & 10 & 38 & 2575 & 1.97 \\
2 & 13 & 45 & 2685 & 1.71 \\
3 & 15 & 54 & 3994 & 1.34 \\
4 & 18 & 35 & 2341 & 1.64 \\
5 & 20 & 20 & 2212 & 1.74 \\
\hline
\end{tabular}

1450-1390 $\mathrm{cm}^{-1}$ due to $\mathrm{C}-\mathrm{H}$ deformation bands, 1160-1120 $\mathrm{cm}^{-1}$ due to $\mathrm{C}-\mathrm{O}-\mathrm{C}$. str vibrations. We quote the bands and their frequencies of poly (MMA-b-AMS) in Table 4. The IR spectrum of Poly (MMA-b-AMS) exhibited all bands belonging to both blocks. The same results are obtained by Mishra et al. [65], H-C. Chiu et al. [66], and $\mathrm{Xu}$ et al. [67]. The structure of the resulting copolymer was confirmed by IR, ${ }^{1} \mathrm{H}-\mathrm{NMR}$ measurements (Figure 5), which demonstrates PMMA-bPAMS has essentially been formed.

\subsubsection{NMR study}

The copolymer poly(MMA-b-a-MS), prepared by the cationic polymerization with $\mathrm{Na}^{+}-\mathrm{MMT}$ as a catalyst, was characterized by ${ }^{1} \mathrm{H}-\mathrm{NMR}$ spectrum. A typical ${ }^{1} \mathrm{H}-\mathrm{NMR}$ spectrum of polymer is schown in Figure 5. In comparing with Figure 6 of the homo-polymer (PAMS), various distributions of MMA and AMS units are observed the results are presented in Table 5.

The signals at 1.2-1.3 and 6.8-7.2 ppm belonged to the methyl and the benzyl groups of PAMS units. The signals at 1.8 corresponding, to methylene protons of PAMS units, a new strong peak at 3.7 ppm appears, This signal is attributed to the protons of the methyl of the ester group in the homosequences of PMMA units, it indicated, that the copolymer P (MMA-b-AMS) was synthesized [65,67]. The presence of PAMS [46] chains causes termination step and lead to the

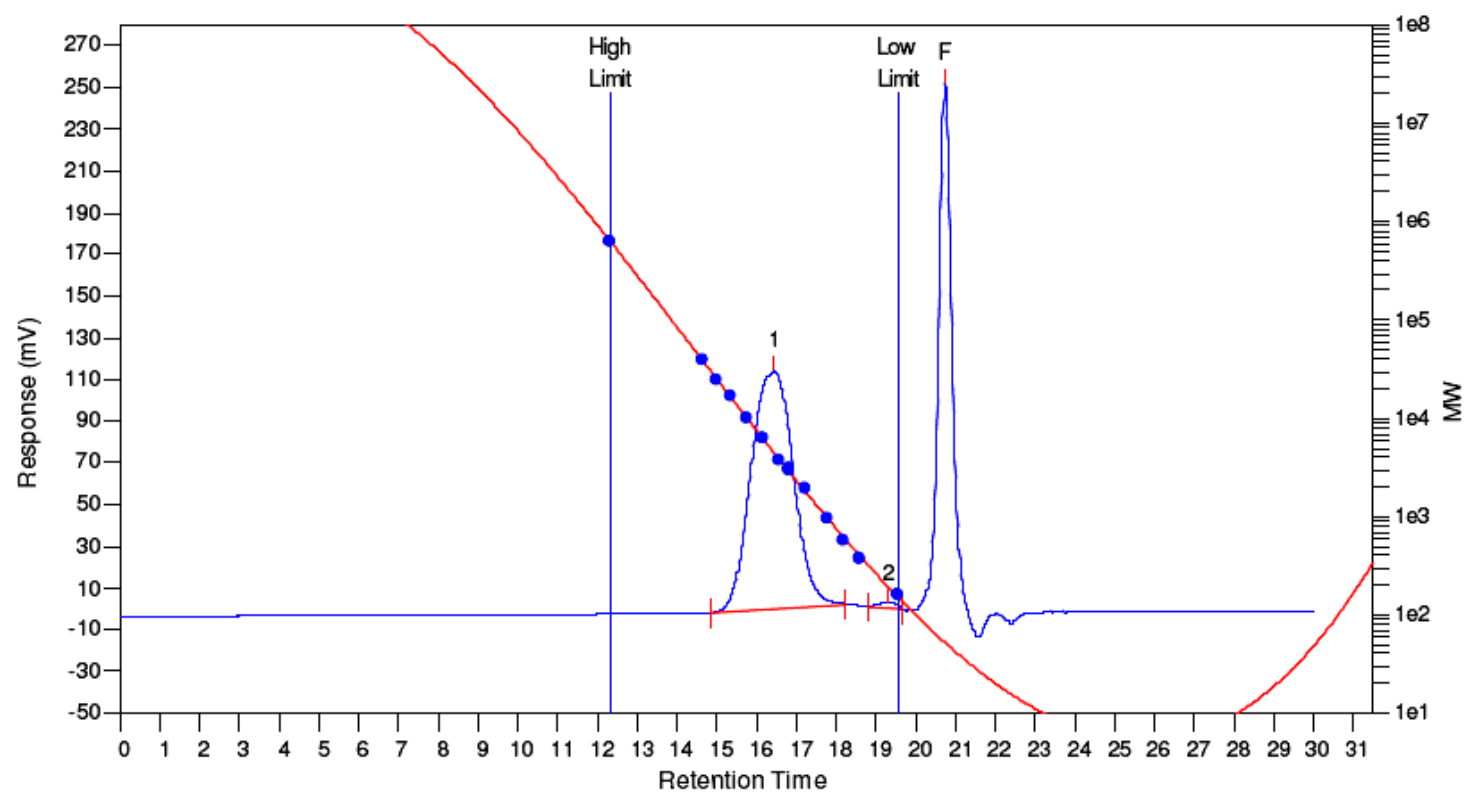

Figure 3. GPC chromatogram of poly (AMS-b-MMA) obtained by $\mathrm{Na}^{+}-\mathrm{MMT}$ catalytic system at $0{ }^{\circ} \mathrm{C}$ : $15 \%$ of $\mathrm{Na}^{+}-\mathrm{MMT}, 30 \%$ AMS and 70\% MMA, $48 \mathrm{~h}(\mathrm{Mw}=5348 \mathrm{~g} / \mathrm{mol}, \mathrm{Mn}=3994 \mathrm{~g} / \mathrm{mol}$, and I=1.34) 
Table 4. The principals bands characteristic of poly(MMA-b-AMS)

\begin{tabular}{lcc}
\hline \multicolumn{1}{c}{ Group } & $v$ experimental in $\mathrm{cm}^{-1}$ & $v$ theoretical in $\mathrm{cm}^{-1}[65,66]$ \\
\hline $\mathrm{C}-\mathrm{H}, \mathrm{CH}_{2}, \mathrm{CH}_{3}$ (str vibrations) & $3000-2960.45$ & 3000 \\
C-H aromatic (deformation bands) & $757.86-544.66$ & $760-550$ \\
C-H methyl, methylene, methyne & $2930-2850$ & $2927-2850$ \\
C-H (deformation bands) & $1489.58-1376.82$ & $1450-1390$ \\
C-C aliphatic (deformation vibrations) & 1028,23 & 1000 \\
C-O-C (str vibrations) and C-C aromatic & $1242.75-1118.83$ & $1160-1120$ \\
C=O str vibrations of ester carbonyl & $1750-1730$ & 1730 \\
C=C aromatic (str vibrations) & 1597.56 & $\sim 1600$ \\
\hline
\end{tabular}

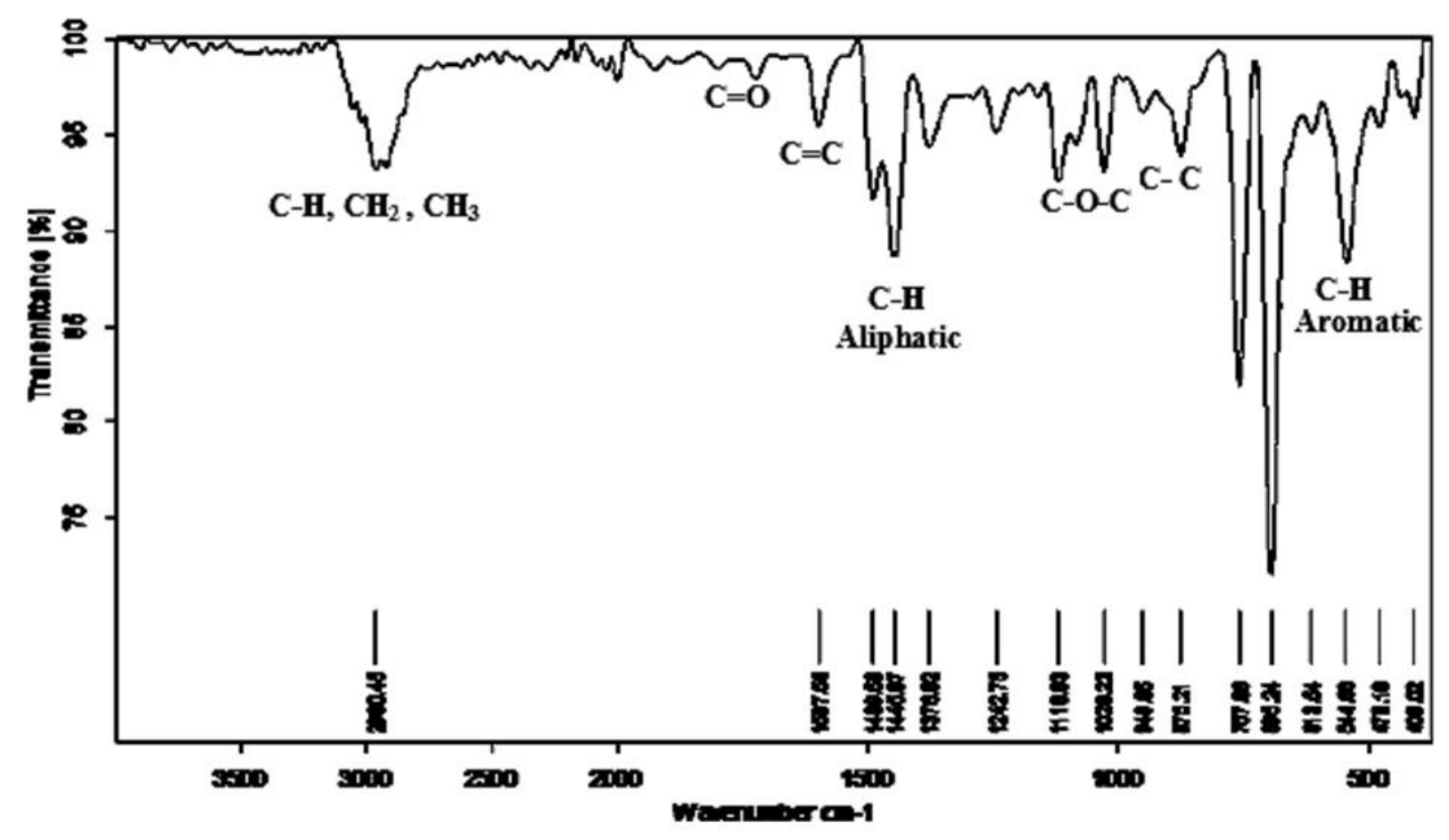

Figure 4. FT-IR spectra of poly(MMA-b-AMS)

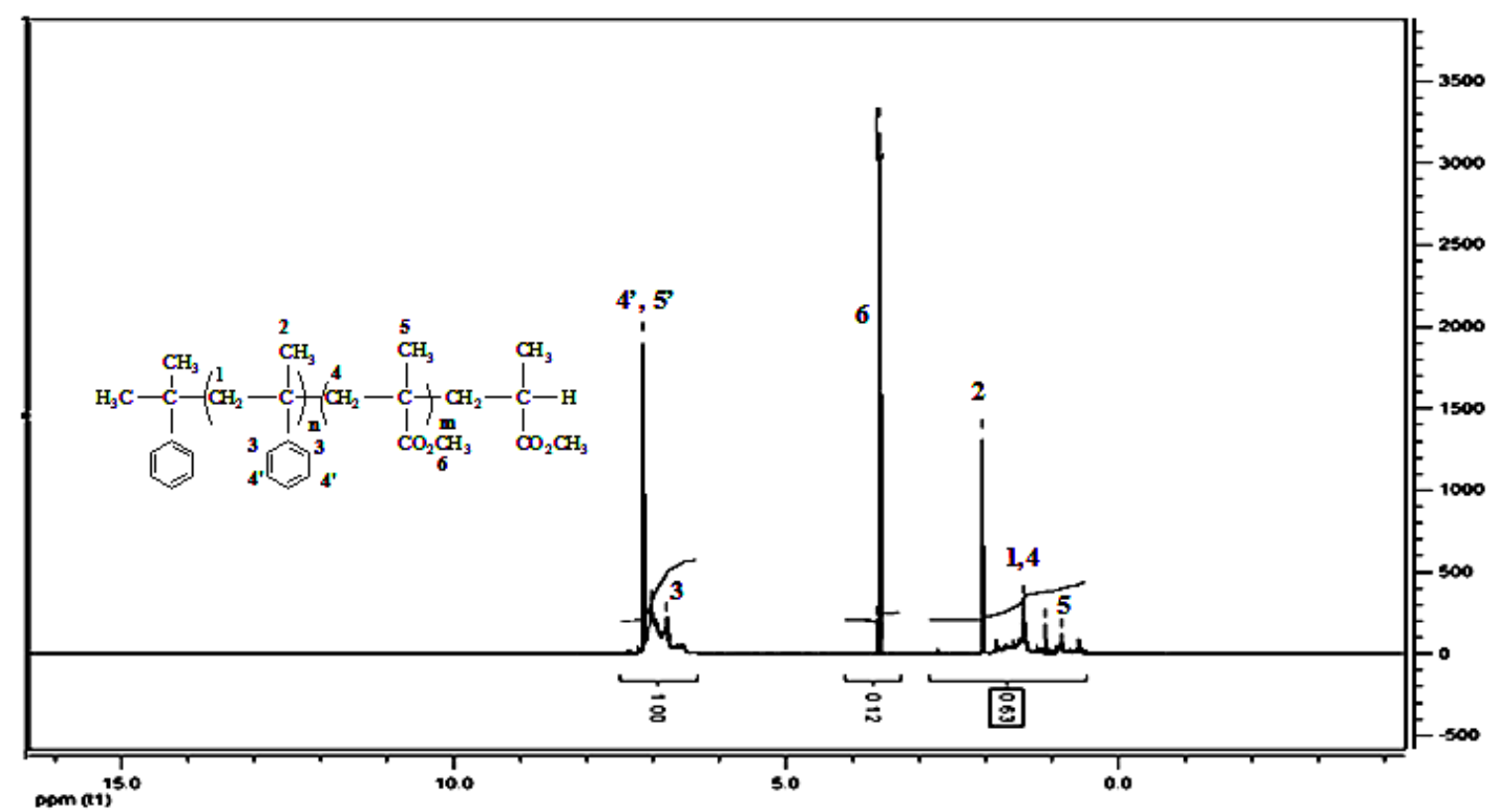

Figure 5. ${ }^{1} \mathrm{H}-\mathrm{NMR}$ spectrum of poly(MMA-b-AMS) $[\mathrm{MMA}=0.03 / \mathrm{AMS}=0.013],\left[\mathrm{Na}^{+}-\mathrm{MMT}=15 \%\right]$; temperature: $0{ }^{\circ} \mathrm{C}$; reaction time: $48 \mathrm{~h}$. 
Bulletin of Chemical Reaction Engineering \& Catalysis, 11 (3), 2016, 323

Table 5. ${ }^{1} \mathrm{H}$ NMR chemical shifts of poly(MMA-b-AMS)

\begin{tabular}{ccc}
\hline Attribution & $\delta(\mathrm{ppm})$ experimental & $\delta(\mathrm{ppm})$ theorical $[67,68]$ \\
\hline $2 \mathrm{H}_{3}+2 \mathrm{H}_{4},+1 \mathrm{H}_{5}$, & 7.17 & $7.2-7,15$ \\
$2 \mathrm{H}_{3}$ & 6.94 & $6.8-6,97$ \\
$3 \mathrm{H}_{6}$ & $3.50-3.78$ & $3.6-3.56$ \\
$2 \mathrm{H}_{2}$ & $2.18-2.86$ & $2.2-2.88$ \\
$2 \mathrm{H}_{1,4}$ & 1.63 & $1.5-1.77$ \\
$3 \mathrm{H}_{5}$ & $0.73-1.25$ & $1.2-0.5$ \\
\hline
\end{tabular}

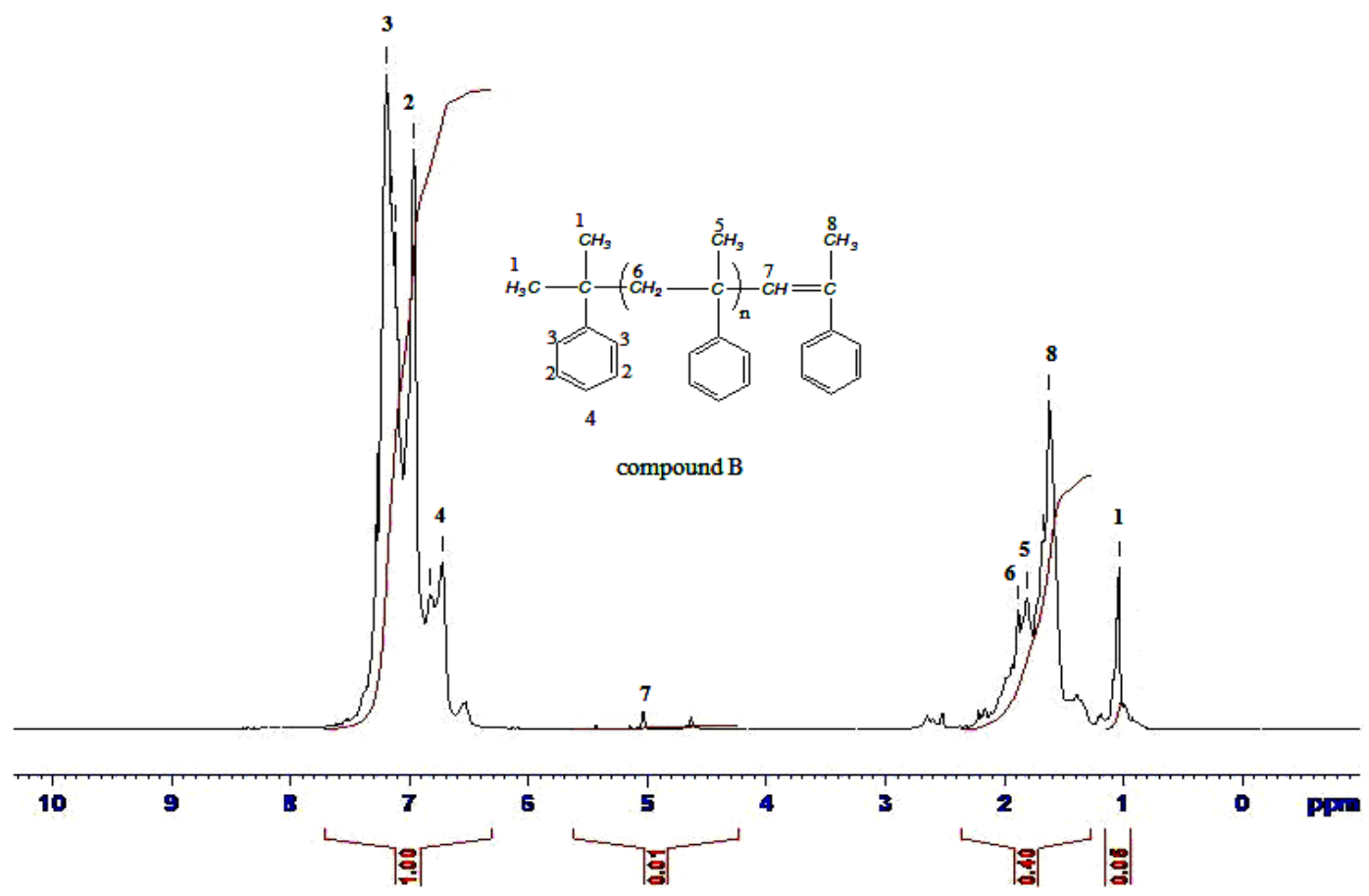

Figure 6. ${ }^{1} \mathrm{H}$ NMR spectrum of PAMS in $\mathrm{CDCl}_{3}$ catalyzed by $\mathrm{H}^{+}$-MMT [46]

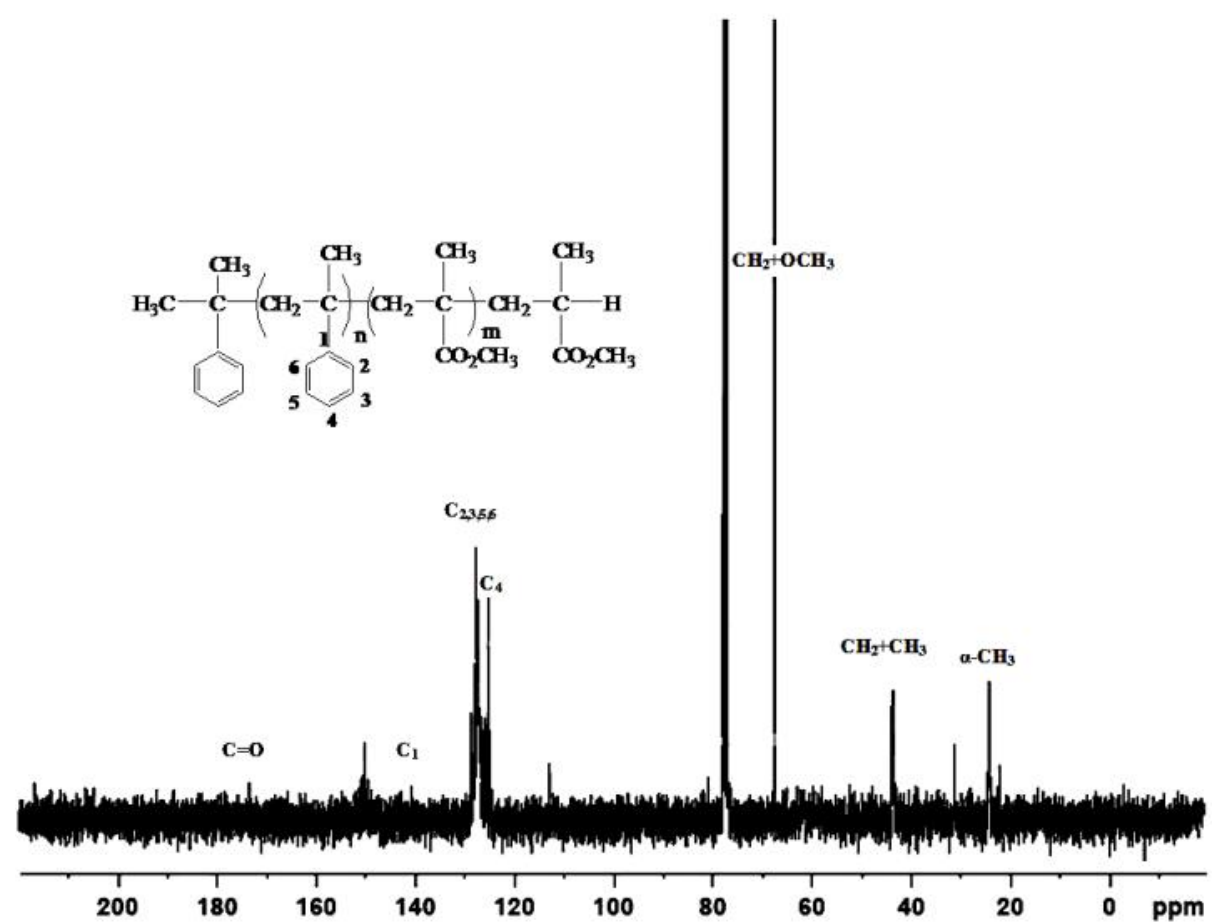

Figure 7. ${ }^{13} \mathrm{C}-\mathrm{NMR}$ spectrum of PAMS/PMMA diblock copolymer 
Bulletin of Chemical Reaction Engineering \& Catalysis, 11 (3), 2016, 324

Table $6 .{ }^{13} \mathrm{C}-\mathrm{NMR}$ Chemicals shifts and signal assignations of poly(MMA-b-AMS)

\begin{tabular}{|c|c|c|}
\hline Attribution & $\delta(\mathrm{ppm})$ experimental & $\delta(\mathrm{ppm})$ theoretical $[68]$ \\
\hline $\begin{array}{c}\mathrm{H} \\
\mathrm{I} \\
-\mathrm{C}\end{array}-\underset{\mathrm{I}}{\mathrm{C}}-\mathrm{CH}_{3}$ & $\mathrm{C}_{1}: 149.32-150.152$ & $\begin{array}{c}\mathrm{C}_{1}: 143.5-145.15 \\
\mathrm{C}_{1}: 145.15-146.8 \\
\mathrm{C}_{1}: 146.8-147.5\end{array}$ \\
\hline $\mathrm{C}_{2,3,5,6}$ & $123.05-128.22$ & $\mathrm{C}_{2,3, \mathbf{5}, \mathbf{6}} 121.7-130$ \\
\hline $\mathrm{C}_{4}$ & 126.18 & $\mathrm{C}_{4}: 126$ \\
\hline 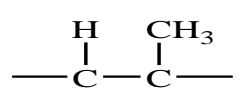 & & $\begin{array}{c}\mathrm{CO}: 177 \\
\mathrm{OCH}_{3}: 47-55\end{array}$ \\
\hline $\begin{array}{cl}\mathrm{l} & \mathrm{I} \\
\mathrm{H} & \mathrm{C}=\mathrm{O} \\
& \mathrm{I} \\
& \mathrm{O} \\
& \mathrm{I} \\
& \mathrm{CH}_{3}\end{array}$ & 43.41-61-15 & $\begin{array}{c}+ \\
\mathrm{CH}_{2}: 47-55\end{array}$ \\
\hline $\mathrm{a}-\mathrm{CH}_{3}$ & $21,81-30.75$ & $16.5-23.0$ \\
\hline $\mathrm{H}_{2} \mathrm{C}-\underset{\mathrm{ph}}{\stackrel{\mathrm{l}}{\mathrm{l}}}$ & $38.45-51.30$ & $44-47$ \\
\hline
\end{tabular}

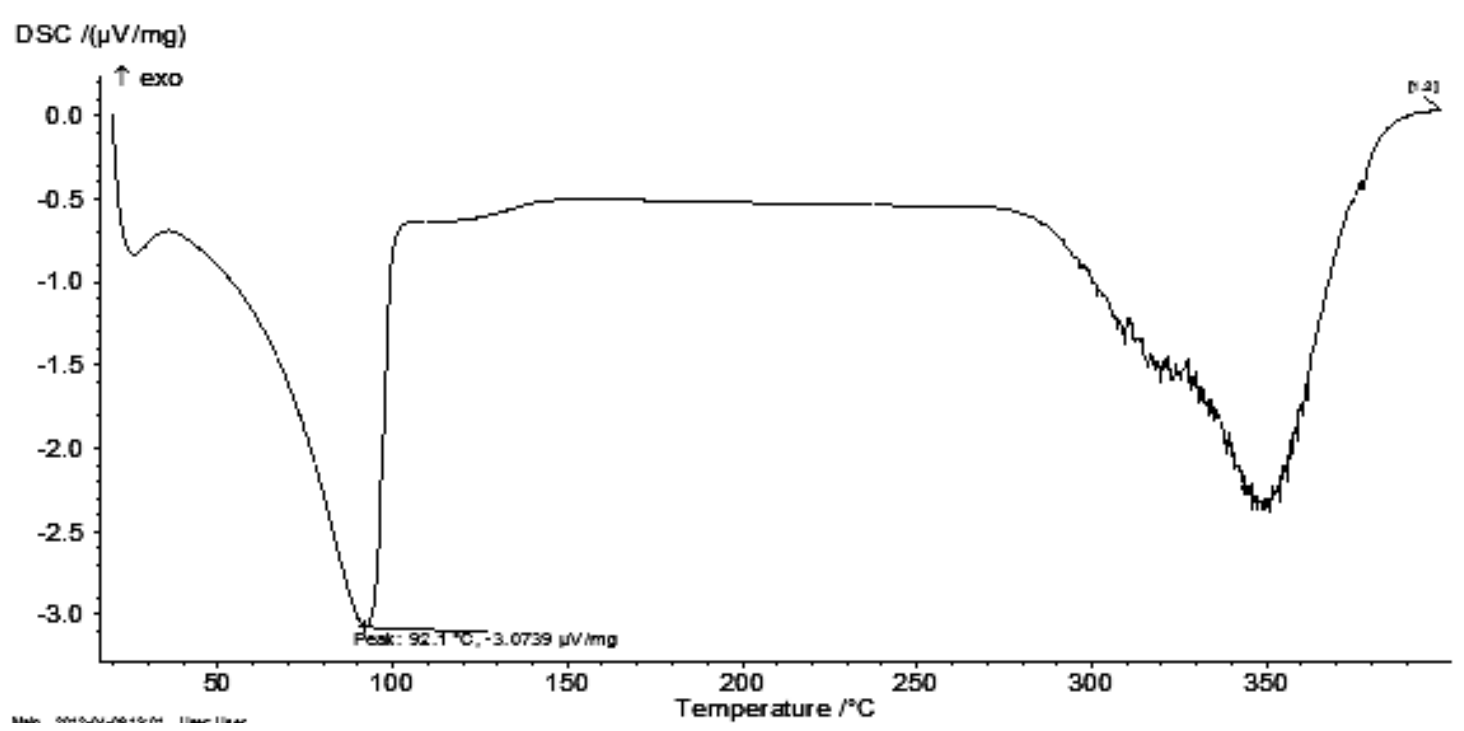

Figure 8. DSC measurements (heating rate $10^{\circ} \mathrm{C} / \mathrm{min}$ ) of Poly (MMA -b-a-MS) copolymers
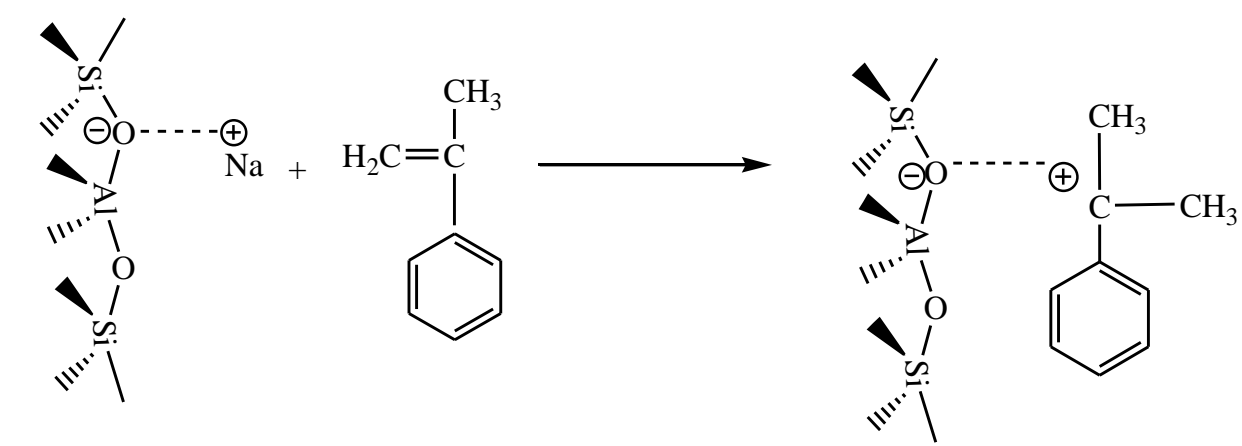

Figure 9. Initiation: fixing of the sodium atom $\mathrm{Na}^{+}$and formation of the first active center 


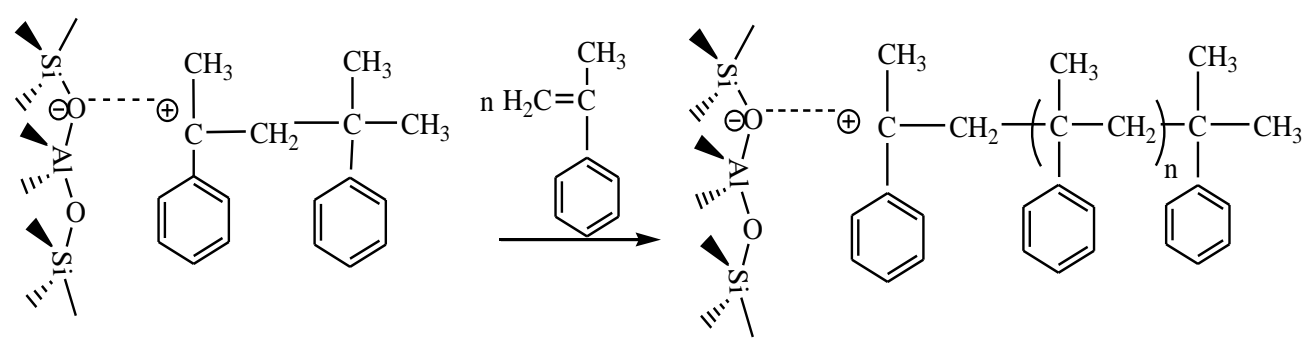

Figure 10. Propagation: the reaction continues with the attack of monomer on the active center formed to lead to the formation of the cation polystyrene. After the formation of cation polystyrene, the attack of the MMA is done of with side or other, and this is due to the possible forms mesomeric of MMA

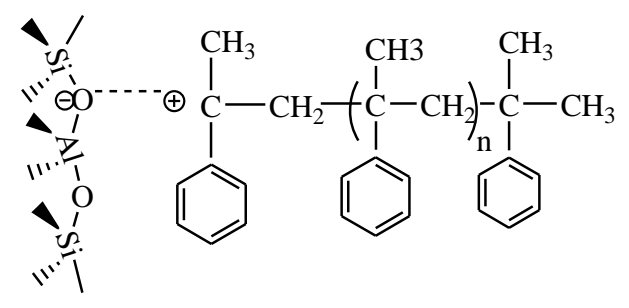

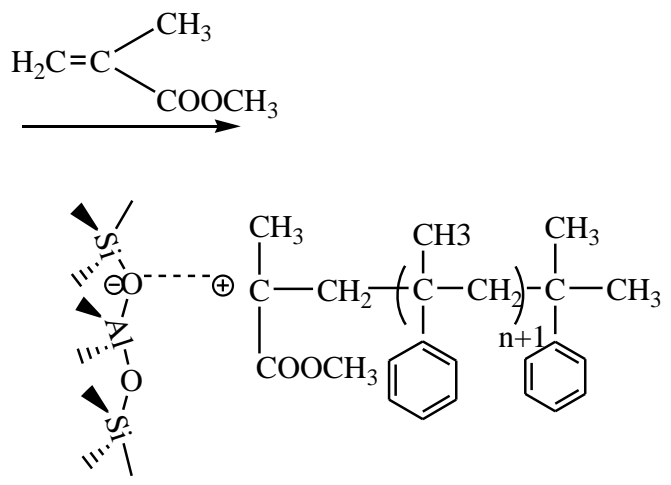

Figure 11. Reinitiating: reaction between the molecule of the MMA and the cation polystyrene<smiles>CC(=O)CCC(C)(C)C(C)(C)CC(C)(CC(C)(C)c1ccccc1)c1ccccc1</smiles>

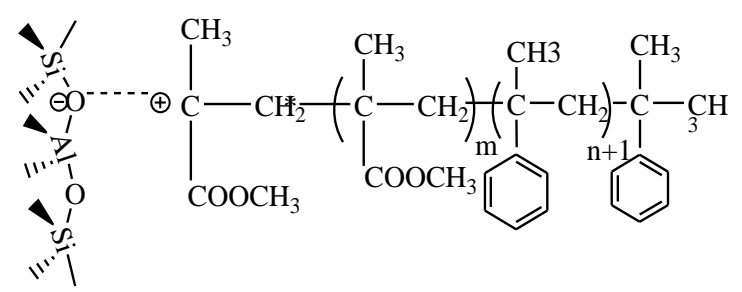

Figure 12. Propagation: after the formation of cation polystyrene, the attack of the MMA is done of with side or other, and this is due to the possible forms mesomeric of MMA

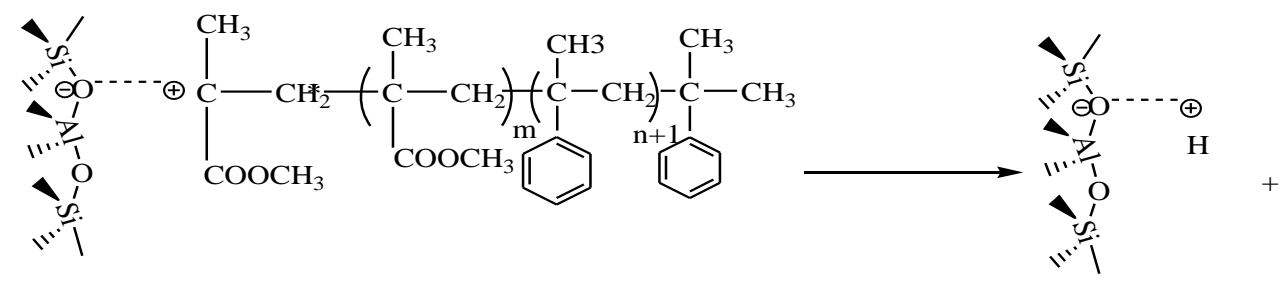<smiles>COC(=O)CC(C)CC(C)(C)C(C)(C)C(=O)OC(C)(C)C(C)(C)c1ccccc1</smiles>

Figure 13. Termination: the reaction ends in a spontaneous transfer of a proton $\mathrm{H}^{+}$ 
block copolymers. The $\mathrm{CH}_{3-}$ end group of PAMS [46] reacts with propagating PMMA chain and produces PAMS/PMMA diblock copolymer (Scheme 1). The same results are obtained in the copolymerization of MMA and Styrene, using different catalysts [65,67]. The ${ }^{13} \mathrm{C}-\mathrm{NMR}$ spectrum Pa-MS/PMMA diblock copolymer is schown in Figure 7. Some assignment results are given in Table 6. The ${ }^{13} \mathrm{C}$-NMR spectrum of the product was also confirmed the structure of PAMS / PMMA diblock copolymer. The same results are obtained by Morejón et al. [68].

\subsubsection{Thermal analysis}

The thermal properties of the copolymers were investigated by differential scanning calorimetry (DSC). Figure 8 shows the results of the DSC measurements. Glass transition temperature $T_{g}$ of the resulting copolymers was observed in the temperature range of $110-140{ }^{\circ} \mathrm{C}$. The DSC analysis of poly(MMA-b-AMS) copolymers show two closely neighbouring melting endotherms at temperatures between 280-290 ${ }^{\circ} \mathrm{C}$, they may be interpreted as crystallites. This analysis indicates the semi-crystalline state of the resulted copolymer.

\subsubsection{Mechanism of Polymerization}

Proposed mechanism of Poly (MMA-b-a-MS) copolymers catalyzed by Mag-H+ was depicted in Figures 9-13. In this mechanism, the initiation is by fixing the sodium atom $\mathrm{Na}^{+}$and formation of the first active center (Figure 9), the propagation is the reaction continues with the attack of monomer on the active center formed to lead to the formation of the cation polystyrene (Figure 10), reinitiating is reaction between the molecule of the MMA and the cation polystyrene (Figure 11), after the formation of cation polystérile, propagation is attacking of the MMA is done of with side or other, and this is due to the possible forms mesomeric of MMA (Figure 12), and termination which the reaction ends in a spontaneous transfer of a proton $\mathrm{H}^{+}$(Figure 13).

\section{Conclusions}

In continuation of the studies on environmentally benign methods using solid supports, it is reported the synthesis of block copolymer poly(MMA-b-AMS) via cationic polymerization by a sodium exchanged Montmorillonite, called $\mathrm{Na}+\mathrm{MMT}$, as a new nontoxic cationic catalyst (Algerian MMT) for vinyl monomers. Na+-
MMT can be easily separated from the polymer product and regenerated by heating to temperature higher than $100{ }^{\circ} \mathrm{C}$. The synthesized copolymer was characterized by Nuclear Magnetic Resonance (NMR- ${ }^{1} \mathrm{H}, \mathrm{NMR}-{ }^{13} \mathrm{C}$ ), FT-IR spectroscopy, Differential Scanning Calorimetry (DSC), and Gel Permeation Chromatography (GPC) to elucidate structural characteristics and thermal properties of the resulting copolymer. The kinetic studies indicated that the polymerization rate is first order with respect to monomer concentration. A possible mechanism of this cationic polymerization discussed based on the results of the ${ }^{1} \mathrm{H}$-NMR Spectroscopic analysis of these model reactions.

\section{Acknowledgement}

Authors are grateful to Pr. Mohammed belbachir professor of Oran University and director of laboratory of polymers chemistry at Oran University in Algeria. Mr. A Addou, engineer of the Chemistry Laboratory of Polymers (LCP) for IR, NMR, XRD and all analysis.

\section{References}

[1] Alexandre, M., Dubois, P. (2000). Polymer layered silicate nanocomposites: preparation, properties and uses of a new class of materials. Material Science and Engineering Report, 28(1-2): 1-63.

[2] Beyer, G. (2002). Nanocomposites: a new class of flame retardants for polymers. Plastics, Additives and Compounding, (10): 22-28.

[3] Rahmouni, A., Harrane, A., Belbachir, M. (2012). Kinetics Study of Catio-Radically Polymerization of Aniline Catalyzed by Maghnite- Na+ Clay Catalyst Layered (Western Algeria). World Journal of Nano Science \& Technology 1: 26-32 .

[4] Binks, B.P. (2002). Particles as surfactants similarities and differences. Current Opinion in Colloid \& Interface Science, 7(1-2): 21-41.

[5] Phan, N.T.S., Brown, D.H., Styring, P. (2004). A Polymer-Supported Salen-Type Palladium Complex as a Catalyst for the SuzukiMiyaura Cross-Coupling Reaction. Tetrahedron Letters, 45(42): 7915-7919.

[6] Maegawa, T., Kitamura, Y., Sako, S., Udzu T., et al. (2007). Heterogeneous $\mathrm{Pd} / \mathrm{C}$ Catalyzed Ligand Free, Room-Temperature Suzuki-Miyaura Coupling Reactions in Aqueous Media. Chemistry-A European Journal, 13 (20): 5937-5943.

[7] Ying, J.Y., Zhang, Y., Hu, D., Patra, P.K. (2009). Polymeric Salts and Poly-NHC-Metal Complexes, US Patent 20090227740. 
[8] Bai, L., Wang, J.-X. (2008). Reusable, Polymer Supported, Palladium Catalyzed, AtomEfficient Coupling Reaction of Aryl Halides with Sodium Tetraphenylborate in Water by Focused Microwave Irradiation. Advanced Synthesis \& Catalysis, 350(2): 315-320.

[9] Mishra, M., Jain, S.K. (2011). Properties and applications of zeolites: A Review. Proceedings of the National Academy of Sciences India Section B-Biological Sciences, 81: 250-259.

[10] Ding, L.H., Zheng, Y. (2007). Nanocrystalline zeolite beta: The effect of template agent on crystal size. Materials Research Bulletin, 42: 584-590.

[11] Pradhan,, N., Pal, A., Pal, T. (2002). Silver Nanoparticle Catalyzed Reduction of Aromatic Nitro Compounds. Colloid Surf. APhysicochem. Eng. Asp. 196: 247-257.

[12] Pogorelić, I., Filipan-Litivić, M., Merkaš, S., Ljubić, G., Capanec, I., Litivić, M. (2007). Rapid, Efficient and Selective Reduction of Aromatic Nitro Compounds with SodiumBorohydride and Raney Nickel. J. Mol. Catal. AChem. 274: 202-207.

[13] Zeynizadeh, B., Setamdideh, D. (2006). $\mathrm{NaBH} 4 / \mathrm{Charcoal}$ : a new Synthetic Method for Mild and Convenient Reduction of Nitroarenes. Syn. Commun. 36: 2699-2704.

[14] Yin, J.M., Zhang, R., Jia, Y.P., Cui, Y.N., Zhou, G.Y., Gao, D.B. (2010). Research Progress in Preparation of Aromatic Amine via Reduction of Aromatic Nitro Compounds. Chinese Chemical Research. 21(1): 96-101.

[15] Kiasat, A.R., Mirzajani, R., Ataeian, F., Fallah Mehrjardi, M. (2010). Immobilized Silver Nanoparticles on Silica Gel as an Efficient Catalyst in Nitroarene Reduction. Chinese Chem. Lett. 21: 1015-1019.

[16] Zhang, X.P., Miao, J.H., Sun, Y.B. (2009). Recent Progress in Selenium Catalyzed Reactions. Chin. J. Org. Chem. 29: 1555-1563.

[17] Alimardanov, A., Schmieder-van de Vondervoort, L., de Vries, A.H.M., de Vries, J.G. (2004). Use of "Homeopathic" Ligand Free Palladium as Catalyst for Aryl-Aryl Coupling Reactions. Advanced Synthesis \& Catalysis, 346(13-15): 1812-1817.

[18] Sołoducho, J., Olech, K., Świst, A., Zajacc, D., Cabaj, J. (2013). Recent Advances of Modern Protocol for C-C Bonds -The Suzuki CrossCoupling. Advances in Chemical Engineering and Science, 3(3A): 19-32.

[19] Colacot, T.J., Carole, W.A., Neide, B.A., Harad, A. (2008). Tunable Palladium-FibreCats for Aryl Chloride Suzuki Coupling with Minimal Metal Leaching. Organometallics, 27(21): 5605-5611.
[20] Pan, C., Liu, M., Zhang, L., Wu, H., Ding, J., Cheng, J. (2008). Palladium Catalyzed Ligand-Free Suzuki Cross-Coupling Reaction. Catalysis Communications, 9(4): 321-323.

[21] Heidenreich, R.G., Kohler, K., Krauter, J.G.E., Pietsch, J. (2002). Pd/C as a Highly Active Catalyst for Heck, Suzuki and Sonogashira Reactions. Synlett, 2002(7): 1118-1122 .

[22] Dasilva, J.C., Defigueiredo, G.M.O. (2002). Spherical catalyst, process for preparing a spherical polyethylene of ultra-high molecular weight, US Patent. 6,384,163.

[23] Galli, P., Vecellio, G. (2004). Polyolefins: the most promising large- Volume materials for the 21st century, Journal Applied Polymer Science Part A: Polymer Chemical, 42: 396415.

[24] Guan, H.L., Xie, Z.G., Tang, Z.H., Xu, X.Y., Chen, X.S., Jing, X.B. (2005). Preparation of block copolymer of epsilon-caprolactone and 2-methyl-2-carboxyl-propylene carbonate. Polymer. 46: 2817-2824.

[25] Qian, L., Yan, Z.F. (2003). Study on the Reaction Mechanism for Carbon Dioxide Reforming of Methane over Supported Nickel Catalyst. Chinese Chemistry Letters. 14: 10811084.

[26] Brunton, S. A., Stibbard, J. H. A., Rubin, L. L., Kruse, L. I., Guicherit, O. M., Boyd, E. A., Price, S. (2008). Potent Inhibitors of the Hedgehog Signaling Pathway. Journal of Medicinal Chemistry, 51: 1108-1110.

[27] Asmafiliz, N., Kılıç, Z., Öztürk, A., Hökelek, T., Koç, L.Y., Açık, L., Kısa, Ö., Albay, A., Üstündag, Z., Solak, A.O. (2009). Phosphorus-nitrogen compounds. 18. Syntheses, stereogenic properties, structural and electrochemical investigations, biological activities, and DNA interactions of new spirocyclic mono- and bisferrocenylphosphazene derivatives. Inorganic Chemistry, 48: 10102-10116.

[28] Ge, H., Hu, Y., Jiang, X., Cheng, D.,Yuan, Y., Bi, H., Yang, C. (2002) Preparation, characterization, and drug release behaviors of drug nimodipine-loaded poly(epsilon-caprolactone)poly(ethylene oxide)-poly(epsiloncaprolactone) amphiphilic triblock copolymer micelles. J. Pharm. Sci. 91: 1463-1473.

[29] Friestad, G.K., Mathies, A.K. (2007). Recent developments in asymmetric catalytic addition to $\mathrm{C}=\mathrm{N}$ bonds. Tetrahedron. 63 (12):25412569 .

[30] Bichuch, N.A., Ganyukhina, T.G., Semchikov, Y.D.(2003). Synthesis of oly(vinylacetatemethyl methacrylate) copolymer microspheres using suspension polymerization, $J$. Appl. Chem., 76: 607-609. 
[31] Li, J., Duan, H., Yu, K., Liu, L., Wang, S. (2010). Characteristic of Low-Temperature Pyrolysis of Printed Circuit Boards Subjected to Various Atmosphere, Resources, Conservation and Recycling, 54: 810-815.

[32] Aguado, J., Serrano, D.P., Miguel, G.S., Escola, J.M., Rodríguez, J.M. (2007). Catalytic activity of zeolitic and mesostructured catalysts in the cracking of pure and waste polyolefins. Journal of analytical and applied pyrolysis. 78 (1): 153-161.

[33] Chae, S., Yi Lee, W.D. (2009). Efficient Dehydrogenation of Amines and Carbonyl Compounds Catalyzed by a Tetranuclear Ruthenium- $\mu$-Oxo- $\mu$-Hydroxo-Hydride Complex. Organometallics. 28(4): 947-949.

[34] Friestad, G.K., Mathies, A.K., (2007). Recent developments in asymmetric catalytic addition to $\mathrm{C}=\mathrm{N}$ bonds. Tetrahedron. 63 (12): 2541-2569.

[35] Zhang, X., Dai, B., Zhua, A., Gonga, W., Liu, C. (2002). The Simultaneous Activation of Methane and Carbon Dioxide to $\mathrm{C}_{2}$ Hydrocarbons under Pulse Corona Plasma Over $\mathrm{La}_{2} \mathrm{O}_{3} / \mathrm{Y}-\mathrm{Al}_{2} \mathrm{O}_{3}$ Catalyst. Catalysis Today. 72: 223-227.

[36] Chae, S., Yi Lee, W.D. (2009) Efficient Dehydrogenation of Amines and Carbonyl Compounds Catalyzed by a Tetranuclear Ruthenium- $\mu$-Oxo- $\mu-\mathrm{Hydroxo-Hydride}$ Complex. Organometallics. 28(4): 947-949.

[37] Ajithkumar, M.P., Yashoda, M.P., Prasannakumar, S. (2012). Copolymerization of N-Vinyl pyrrolidone with methyl methacrylate by $\mathrm{Ti}(\mathrm{III})$-DMG redox initiator. Turk. J. Chem., 36: 397-409.

[38] Horak, D., Benes, M.J. (2000). Macroporouspoly(vinylpyrrolidone-coethylene dimethacrylate) beads by suspension polymerization, React. Func. Polym., 45: 189195.

[39] Zheng, Y., Shen, Z., Cai, C., Ma, S., Xing, Y. (2009). The Reuse of Nonmetals Recycled from Waste Printed Circuit Boards as Reinforcing Fillers in the Polypropylene Composites, Journal of Hazardous Materials, 163: $600-606$.

[40] Brar, A.S., Kumar, R. (2002). Microstructure analysis of N-vinyl-2-pyrrolidone/vinyl acetate copolymers by NMR spectroscopy, Polym. Int., 51: 519-529.

[41] Ye, W.P., Du, F.S., Jin, W.H., Yang, J.Y., Xu, Y. (1997). In vitro degradation of poly(caprolactone), poly(lactide) and their block copolymers: Influence of composition, temperature and morphology. React. Funct. Polym. 32: 161-168.
[42] Qian, L., Yan, Z.F. (2003). Study on the Reaction Mechanism for Carbon Dioxide Reforming of Methane over Supported Nickel Catalyst. Chinese Chemistry Letters. 14:10811084 .

[43] Fukuda, K., Liu, B., Nakatani, H., Nishiyama, I., Yamahiro, M., Terano, M. (2003). Significant variation of molecular weight distribution (MWD) of polyethylene induced by different alkyl-Al cocatalysts using a novel surface functionalized $\mathrm{SiO}_{2}$ supported Ziegler-Natta catalyst, Catalyst Communication, 4: 657-662.

[44] Belbachir, M., Bensaoula, A. (2006). US Pat. 7-094-823 B2.

[45] Bhargava, S.K., Akolekar, D.B., Foran, G. (2007). Investigations on gold nanoparticles supported on rare earth oxide catalytic materials. Journal of Molecular Catalysis A: Chemical 267: 57-64.

[46] Ayat, M., Harrane, A., Belbachir, M. (2008). Maghnite- $\mathrm{H}^{+}$a solid catalyst for the cationic Polymerization of a-methylstyrene, J. Appl. Polym. Sci., 109: 1476-1479.

[47] Ferrahi, M.I., Belbachir M.(2004). Preparation of poly(oxybutyleneoxymaleoyl) catalyzed by a proton exchanged montmorillonite clay, Molecules, 9: 968-977.

[48] Zohuri, G.H., Jamjah, R., Ahmadjo, S. (2006). Comparative study of propylene polymerization using monosupported and bisupported titanium-based Ziegler-Natta catalysts. Journal Applied Polymer Science, 100: $2220-2226$.

[49] Ferrahi, M.I., Belbachir, M. (2005). Synthesis of cyclic polyesters of poly (oxybutyleneoxymaleoyl), Journal of Polymer Research,12:167-171.

[50] Arcadi, A. (2008). Alternative Synthetic ethods through New Developments in Catalysis by Gold, Chemistry Review. 108: 3266-3325.

[51] de la Pena O'Shea, V.A., Consuelo, A.G.M., Platero, P.A.E., Campos-Martin, J.M., Fierro, J.L.G. (2011). Direct Evidence of the SMSI Decoration Effect: the Case of $\mathrm{Co} / \mathrm{TiO}_{2}$ Catalyst. Chem. Commun., 47 (25): 71317133.

[52] Li, Z., Meng, M., You, R., Ding, T., Li, Z. (2012). Superior Performance of Mesoporous $\mathrm{TiO}_{2}-\mathrm{Al}_{2} \mathrm{O}_{3}$ Supported NSR Catalysts with the Support Synthesized Using Nonionic and Cationic Surfactants as Co-Templates. Catal. Lett., 142 (9): 1067-1074.

[53] Zhou, Y., Qiu, K. (2010). A New Technology for Recycling Materials from Waste Printed Circuit Boards, Journal of Hazardous Materials, 175: 823-828. 
[54] Yahiaoui, A., Belbachir, M., Hachemaoui, A. (2003). Cationic polymerization of 1,2epoxypropane by an acid exchanged montmorillonite clay in the presence of ethylene glycol, International Journal of Molecular Sciences, 4: 572-585.

[55] Chabani, M., Yahiaoui, A., Hachemaoui, A., Belbachir, M. (2011). New Approach for the Polymerization of 2-Chloroethyl Vinyl Ether Using a Maghnite Clay as Eco-Catalyst. J. Appl. polym. Sci. 122, 1800-1806.

[56] Rahmouni, A., Harrane, A., Belbachir, M. (2012). Kinetics Study of Catio-Radically Polymerization of Aniline Catalyzed by Maghnite- $\mathrm{Na}+$ Clay Catalyst Layered (Western Algeria). World Journal of Nano Science \& Technology 1: 26-32 .

[57] Harrane, A., Belbachir, M. (2007). Synthesis of Biodegradable Polycaprolactone/ Montmorillonite Nanocomposites by Direct Insitu Polymerization Catalysed by Exchanged Clay. Macromol. Symp. 247: 379384 .

[58] Kono, H., Mori, H., Terano, M. (2001). Novel olefin block copolymer, polypropene-blockpoly (methylene-1,3-cyclopentane-co-propene), synthesized from propene and 1,5-hexadiene by a modified stopped-flow method, Macromolecular Chemical Physics, 202: 13191326.

[59] Chae, S., Yi Lee, W.D. (2009). Efficient Dehydrogenation of Amines and Carbonyl Compounds Catalyzed by a Tetranuclear Ruthenium- $\mu$-Oxo- $\mu-\mathrm{Hydroxo-Hydride}$ Complex. Organometallics. 28(4): 947-949.

[60] Mohamed, A.R., Zakaria, Z., Zulkali, M.D. (2010). Catalytic Hydrogenation of Carbon Dioxide by Platinum Doped Nickel Oxide Catalysts. Catalysis World Applied Science Journal. 8: 490-495.
[61] Bentonite, U., Wyoming, USA. (1950). Analytical Data Reference, Clay. Min, Report $\mathrm{N}^{\circ}$ 7. Amer Petro. Int. Project 49, 62. Burge, D. E and Bruss, D. B. J. Polym. Sci. Part A: Polym. Chem. 1963, 1, 927.

[62] Rahmouni, A., Harrane, A., Belbachir, M. (2013). Maghnite- $\mathrm{H}^{+}$, an eco-catalyst layered (Algerian Montmorillonite) for synthesis of polyaniline/Maghnite clay nano-composites. Int. J. Chem. Mater. Sci., 1(6): 175-181.

[63] Ren, L., Pan, X. (2011) Catalysts used for microwave-assisted TCE decomposition by hydrogen. Catalysis Communications 12(14): 1366-1369.

[64] Ni, M., Xiao, H., Chi, Y., Yan, J., Buekens, A., Jin, Y., Lu, S. (2012). Combustion and Inorganic Bromine Emission of Waste Printed Circuit Boards in a High Temperature Furnace, Waste Management, 32: 568-574.

[65] Ni, M., Xiao, H., Chi, Y., Yan, J., Buekens, A., Jin, Y., Lu, S. (2012). Combustion and Inorganic Bromine Emission of Waste Printed Circuit Boards in a High Temperature Furnace, Waste Management, 32: 568-574.

[66] Guo, J., Cao, B., Guo, J., Xu, Z. (2008). A Plate Produced by Nonmetallic Materials of Pulverized Waste Printed Circuit Boards, Environmental Science and Technology, 42: 5267-5271.

[67] Huang, B., Bartholomew, C.H., Woodfield, B.F. (2013). Facile Synthesis of Mesoporous Alumina With Tunable Pore Size: Effects of Alcohols in Precursor Formation and Calcination. Microporous Mesoporous Mater., 177: 37-46.

[68] Siew, K.W., Lee, H.C., Gimbun, J., Cheng, C.K. (2014). Production of CO-rich hydrogen gas from glycerol dry reforming over Lapromoted $\mathrm{Ni} / \mathrm{Al}_{2} \mathrm{O}_{3}$ catalyst. International Journal of Hydrogen Energy, 39: 6927-6936. 